Max-Planck-Institut für demografische Forschung

Max Planck Institute for Demographic Research

Konrad-Zuse-Strasse 1 - D-18057 Rostock - GERMANY

Tel +49 (0) 3812081 - 0; Fax +49 (0) 3812081 - 202;

http://www.demogr.mpg.de

MPIDR WORKING PAPER WP 2003-009

APRIL 2003

\title{
Two theoretical interpretations \\ of the dissonance between fertility intentions and behaviour
}

Giuseppe A. Micheli (giuseppe.micheli@mi.unicatt.it)

Laura Bernardi (Laura_Bernardi@ brown.edu)

This working paper has been approved for release by: Jan M. Hoem (hoem@ demogr.mpg.de)

Head of the Laboratory of Contemporary European Fertility and Family Dynamics.

(C) Copyright is held by the authors.

Working papers of the Max Planck Institute for Demographic Research receive only limited review.

Views or opinions expressed in working papers are attributable to the authors and do not necessarily reflect those of the Institute. 
Title:

\section{Two theoretical interpretations of the dissonance between fertility intentions and behaviour.}

First author: Professor Giuseppe A. Micheli,

Affiliation: Universita' Cattolica del Sacro Cuore, Milan, Italy

Tel: $\quad 0039-02-72342496$

Fax: 3390272342724

E-mail: giuseppe.micheli@mi.unicatt.it;

Second author: Dr. Laura Bernardi,

Affiliation: Max Planck Institute for Demographic Research, Rostock, Germany

Tel: $\quad 001-401-863-3752$

Fax: 001-401-863-3351

E-mail: Laura_Bernardi@brown.edu; 


\section{Short abstract:}

In the paper we outline two possible theoretical interpretations for the inconsistency often observed between fertility intentions and fertility behaviour. We draw on sociopsychological models of human behaviour which emphasise the role of normative-affective factors on decision-making processes.

The first interpretation is based on the observation that family and fertility choices are gradually shifting from a zone where behaviour is normative regulated to a zone of normative indifference, where mere rational decision-making based on cost-benefit considerations is at work. The dissonance between fertility choices and declared intentions depends on the fact that the former are based on rational considerations, while the latter are still constrained by a normative familistic philosophy.

The second interpretation assumes the existence of an interposing mechanism in the sequence expectations-behaviour. These mechanisms, as anxiety and avoidance dispositions, filter the passage from individual value orientations in the affective sphere to their actual behaviour.

We base our argument on two sets of information. First, we use a survey which allows us to construct empirical indicators of psychological dispositions connected to expectations related to family and fertility behaviours (Abacus 1996, Italy). Second, we analyse 54 non-structured interviews conducted in Northern Italy, which give a detailed picture of the hypothesised mechanisms and suggest new directions for research. 
The three princes of Serendip were continuously making accidental discoveries of things they were not seeking $(H$. Walpole)

\section{How to reconcile the inconsistency between preferences, intentions and behaviours}

\section{A normative - affective approach}

In recent Italian demographic surveys there is a persistent inconsistency between declared intentions and demographic behaviours. Even where researchers find a stronger correspondence between the two, declared expectations have predictive power only on a rather limited temporal horizon, 'among young adults for whom the family-life event in question is the 'next in line' (Liebfroer, 1999).

With the substitution of individual priority to family priority, the Mediterranean familistic model perhaps undergoes a radical change: there would not be longer a case for an "amoral familism", but rather for an "amoral individualism", as Banfield correctly pointed out (1958). Resulting from the shift from a "team" familism to an amoral individual familism, the new family model would now appear to constitute an extraordinarily stable model because it is rationally optimal. However two questions need to be answered: a) how to explain the drift over the past few years? and b) how to explain the discrepancy between attitudes, norms and actual behaviour? In this paper we limit our effort to answer the second of these questions. As an explanation of human action one of the virtues of the neoclassical paradigm is that it provides a clear, concise and simple conception of the human nature it presupposes, although, the thumb rule 'better is cheaper' should also be applied to theory building. Less parsimonious theoretical approaches than pure rational decision- 
making might explain both inconsistencies among intentions and/or behaviours, as well as the changing of social practices. In this paper we argue for the possibility of interpreting the inconsistencies between fertility behaviour and declared intentions with two distinct models, both consistent with a more general normative-affective approach. One is what we have called a neutralisation and rational choice model (section 2), the other one is a model with interposing mechanisms (section 3). In delineating these two models, we draw on such different theoretical traditions as rational action theory, social interaction, and mother-child attachment and we apply them to the demographic field of fertility studies. Our approach is strongly influenced by concepts introduced by two authoritative references in rational action theory. One is the idea of routine behaviour proposed by Leibenstein $(1981)^{1}$ : reflecting on the logic of procreative choices, Leibenstein affirms that "a high proportion of fertility rate is determined by 'non-decision decisions'", and continues as follows:

We assume that active decision-making is infrequent. Day-to-day behaviour is on a routinised basis. Passive decisions usually involve routine behaviour. It may be viewed as behaviour 'within a holding pattern' (..). If the event is strong enough and has a significant impact on the assessment of the decision-maker about the outcomes of behaviour, then the impact of the event forces itself on the attention of the decision-making entity. In this way the event may activate the idea that a new, active decision may have to be made (..). We assume that within certain bounds of certain variables the routines in behaviour that occurred in the past simply continue. Only if the changing data go beyond the lower or upper bounds of the inert area does a stimulus arise for active decision-making

The second concept is that of boundaries delimiting a zone of legitimate indifference in which rationality is at work, i.e. the thesis advanced by Etzioni (1992), whereby:

The majority of choices people make, including economic ones, are completely or largely based on normative/affective considerations not merely with regard to selection of goals but also of means, and (..) the limited zones in which other, logical-empirical considerations are paramount, are themselves defined by 
normative/affective factors that legitimate and otherwise motivate such decision making.

Etzioni affirms that "normative/affective factors influence the selection of means by many ways", but he underlines three of these in particular:

Excluding the role of logical-empirical considerations in many areas; infusing the deliberations in such a way that logical-empirical considerations play a relatively minor or secondary role to normative/affective factors; (fencing) the rational decision making into specific normative/affective indifference zones.

\section{Two possible explanations}

Coale's oft-evoked third necessary precondition for the first fertility transition to start states that an ideational change is needed: birth control should enter the domain of conscious choice through the readiness to use contraception (Coale 1973) $)^{2}$. Similarly, it is well-known that in low fertility societies we spend on average the first 10-15 years of reproductive life not procreating. When having children is easily avoidable ${ }^{3}$, and avoided for years, it is plausible to infer that an active decision to have a child and a consequent change in contraceptive behaviour are necessary. The core idea is that there might be limits to initiate conscious decision-making associated with these behaviours. The absence of a behavioural performance does not need to be interpreted necessarily as the outcome of a negative choice. Instead of regularly evaluating one's decision and at each time concluding that it is best not to have a child at the given moment, individuals might face the absence of decision-making itself, that is the removal of childbearing consideration from consciousness. Individuals do not always face such a choice in terms of weighing its advantages or disadvantages, and 
what is considered to be a delay in a chosen behaviour could actually be a delay in the process of choosing ${ }^{4}$.

We refer to a recent tradition of studies concerning the normative-affective mechanisms of social action. On the one hand we draw on Janis and Mann's (1977) analysis of the role of affection in the decision-making process ${ }^{5}$ and on the already mentioned normative-affective approach developed by Etzioni (1986) ${ }^{6}$, and on the other hand we draw upon Leibenstein's (1988) concept of 'inert area', ${ }^{, 7}$ on the role of environmental pressure on decision-making effectivness (Yerkes-Dodson Law 1908, Broadbent 1971) ${ }^{8}$.

Stemming from Janis \& Mann's, Etzioni's and Leibestein's categories, two alternative models can therefore explain delays and foregone childbirth in a lowest-low fertility context. These models are diagrammed in Fig 1. According to the first model, we take into account that childbearing choices gradually shifted from the area of normative regulation into the area of affective neutrality, where they can be evaluated by costs and benefits parameters. The present shift into the region of legitimate indifference allows for environmental pressure to act on the decision-making process, which was previously located below the level of consciousness. Therefore the declared expectations consistent with the normative framework are countered by the perceived costs of childbearing and childrearing. This paralysing combination has the effect of putting off decisions and behaviours.

According to the second model of interpretation, there exist some dispositional states, or moods, interposing themselves in the sequence expectations-behaviours, as the interceptors in a cerebral synapses ${ }^{9}$. If these dispositions change, the behaviour and the definition of the environment change as well. Therefore expectations are still conforming to the normative 
framework, but decisions and behaviour are hindered by blocking moods, and declared high costs are just a rationalisation ex post to reconcile expectations and actual behaviour.

In the next sections we will further illustrate these two models.

\section{FIGURE 1 ABOUT HERE}

\section{A first hypothesis}

\section{Affective neutralisation and rational choice}

In our first interpretation, we start from the assumption that fertility choices are gradually shifting from a normative zone to a zone of "legitimate indifference", where rational decision-making based on cost-benefit considerations are not constrained by individual affective elements. In our view, the consequence of such a shift implies the existence of a cognitive dissonance between actual behaviours, that is delaying family and fertility transitions, and declared intentions, constrained within the persisting cage of a 'familistic' philosophy (the "Italian paradox" at the macro level ${ }^{11}$, can be seen as a dissonance at the individual level).

Elster (1983) observes that the fox who is after the grapes, but for some reason cannot reach them, will be subject to an internal pressure aimed at reducing the dissonance. It will tend to diminish the value of the grapes and change either its system of preferences ("I don't like them anyway") or its belief system ("the grapes are sour"). Let us suppose that having a child remains a desirable goal for the younger cohorts "trapped" in the familistic philosophy, but that for some reasons this goal is perceived as having become too hard to achieve. A reduction of dissonance between these two cognitive elements, that are the desirability of the 
goal and the difficulty of its achievement, may be obtained by modifying one of these two elements as the fox of the tale does: a) altering some attribute of the goal desired, in order to decrease its desirability - e.g. attributing irreversibility to family transitions and therefore perceiving them as an infinite cost - or b) changing the system of beliefs, e.g. overestimating the actual costs for the achievement of the goal to the point of scoring a negative cost benefit balance in favour of abandoning the goal.

If one of the two strategies was adopted, we would surely expect less stress on the institution of the family and on its irreversibility, to reduce its costs, or a change into declared expectations. On the contrary, some Italian regional surveys, as the Friuli survey (Billari, Micheli, 1999), have shown that there is evidence among the younger cohorts of a clear-cut bifurcation between declared expectations, which are socially-normed, and "rational" demographic choices limiting fertility within the family. The dissonance between expectations and reality seems to be wide and lacerating, while at the same time there is no attempt underway in order to reduce it. While in other European countries the flexibility of the institutions is increasing and fertility scores higher levels, the persistence of a familistic model in Italy brings as a consequence a reduction in family size and a lengthening of the intervals between births. (Dalla Zuanna 2001). Among the younger Italian cohorts, perception of the costs associated with family formation increases, although this does not affect the perception of their positive value and their irreversibility. The grapes are definitively not sour, but they are out of reach. Therefore the dissonance stays and behaviours are put off. 
The system of declared preferences seems not to adapt to the system of beliefs of what is viable. This first line of interpretation requires a closer look at the role of social interaction in the shaping of individual system of beliefs and of its normative framework, through processes of social learning and social influence. Assuming that these two processes are at work means admitting that definition of the situation (normative framework and system of beliefs) are dependent not only on individual characteristics, but also on the characteristics and behaviours of those composing personal networks.

\section{Qualitative approach}

One of the two empirical approaches used in this paper to develop our hypothesis is the qualitative analysis of non-structured interviews conducted in winter 2000-2001. Interviewees are women aged 30-39, in stable unions (whether marriage or cohabitation) for at least 2 years and resident in the region for at least 10 years. Respondents were drawn from the Indagine Sociale Lombarda (ISL-2000), carried out by the IReR (Istituto Regionale di Ricerca of Lombardy) a few months before ${ }^{12}$. The interviews were tape-recorded, transcribed in their entirety, and subsequently codified. The interviews were collected to investigate the relatively unexplored field of conversations and observations concerning their fertility choices involving the respondent and the relevant people composing her social network.

Theoretical insights can be gained by the systematic observation of in depth interview data, since a qualitative approach allow using the information contained in the narratives (affective and cognitive components of the narrative, contradictions, spontaneous 
recollection and sequencing of events) ${ }^{13}$. At the moment of the interview, it was possible to probe for more clarification. At the moment of analysing the transcripts, it was important to check for the internal consistency of the overall interview message before assigning one concept to one category or the other. In the analysis we will interpret the presence of conflicting statements as well as the presence of affective vs. cognitive components into respondents' argumentation (Cicourel 1974, Crittenden 1999).

The open-interview guideline includes information on (1) the general socio-demographic characteristics of respondents', their families, their partner's families; (2) family, educational and working aspirations in the past and in the current situation; (3) events and perceptions related to the family formation process; (4) important people outside the household, their relationships with members of the network and their family choices in different phases of the respondent's life cycle; (5) conversations referring to family issues with network members; (6) expected and observed changes in social network and life organisation with birth (for each child), and future fertility intentions.

Initial coding of the interviews consisted in labelling and categorising the processes under study (different form of social interaction related to family formation) as indicated by the data. Interviews were fragmented into extracts answering simple questions like "what", "where", "who", and "when" characterising the event described. Subsequently, extracts were compared and similar incidents grouped together under the same conceptual label. At a more abstract level, concepts were again joined into categories. In the following section, we outline different typologies of normative attitudes towards family, derived from the analysis based on constant comparison of different extracts (Boejie 2000). 


\section{Profile of attitudes towards family formation}

In our analysis of the interviews we identified four typologies of women according to their position regarding some relevant aspects of family formation. When the perceptions of event and conversations of the women are viewed as systematically rooted in their underlying attitudes towards family, the importance of this reading key emerges clearly. Common patterns in their answers induced us to distinguish women into four kinds of attitude systems, two stable ones ${ }^{14}$ - the traditional familistic one (16) and the and postfamilistic one (3) and two unstable ones - the individualist familistic (17) and the neo postfamilistic in transition (18). This distinction is made on the basis of the classification of the meaning of children in the union, the expressed opinion on a woman's role within the couple and the family, the attitude in considering the possible economic and time costs of childbearing and childrearing ${ }^{15}$. In the stable typologies, attitudes about family formation and other aspect of life are consistently related to each other building a value system rather resistant to changes. In the unstable typologies, attitudes on the same topic rather conflict with each other, favouring the shifting of family formation choices to the zone of emotional indifference we referred to in section 1.

We schematically describe the four typologies here below:

a) Traditional familists (stable) are characterised by considering marriage and children as a package and life as a single or a childless marriage as selfish choices. Inter-generational links are valued and encouraged. Family formation costs are given; they are fixed conditions to be faced once the commitment to build a family is made with marriage, and decisions in 
this regard are not re-examined in every contingency. Balancing time between work and family means privileging one's family anytime when one's financial situation allows it. Focus is on the expression of satisfaction with the decision made. The woman primary role is being a "good mother". Economic hardship might justify the presence of the woman in the labour market besides her role in the household, but these two roles are in a built-in conflict, since "woman" should ideally coincide with "wife" and "mother". In other words working is a necessary sacrifice that subtract the woman to her main occupation and does not have any positive value but the monetary reward in itself. Neither for the woman, nor for the other members of the family.

b) Individualistic familists (unstable) see marriage as a fundamental social obligation with economic basis. Having at least one child is an integral part of the marriage contract, because the self-fulfilment that the couple derives from it reinforces the contract. Balancing this benefit with the costs implied in childbearing and rearing determines family size and timing. Decisions on the latter are updated several time during the life course depending on cost considerations, since the priority is not the family but the couple and the individualities within the couple. If the woman self-realisation is outside the household, then it has to be pursued, either delegating childrearing or renouncing parenthood when it is in conflict with other aspirations. The built-in conflict is solved with alternatives to parents' child rearing.

c) Neo-postfamilists (unstable) think about a stable union (not necessarily marriage) not as an economic contract but rather as a substantively "meaning giving system" and parenthood is principally an expressive role. Therefore union or marriage can be reversible. Costs as for the individualistic families are carefully considered to be balanced with other 
individual exigencies, and past and future choices are monitored. The high significance of family transitions means that they are to be made only when individuals feel "ready", at the cost of indefinitely postponing them. Recurrent references to renounces and sacrifices go together with the observation that marrying or entering parenthood is a consequence of a clear and valuable choice in favour of the role of being a wife or a mother. It remains important to differentiate the woman from the mother and to perform both roles actively.

d) Postfamilists (stable form) women see marriage and having children as a possibility among others and not as a way to give a unique "meaning" to their union. Costs are considered with respect of the well-being for the couple and, as in the case of the other stable system of attitudes - the traditional familistic one - costs are given and do not lead to frequent reconsideration of choices. Solution for childcaring is weaving. Though the content of the choices varies according to different definitions of well being. In fact the stress on individual identity and self realisation is maintained even after a family is formed. Preserving one's on roles harmoniously is a pre-condition to adding a new role, and therefore ideally there is no conflict between being a mother and being a woman.

Table 2 contains a partial example of the way our evidence was organised and used to build the resulting typologies.

\section{TABLE 2 ABOUT HERE}

\section{Social processes and personal networks}

We refer to these social processes considering exclusively direct social interaction between the individual and his/her networks of peers, whether verbal or not. When social 
interaction with family members and peers provides the individual with information that affects subjective beliefs, either modifying or reinforcing them, we refer to this process as social learning. Family and fertility observations and conversations with others may alter the perception of related costs and benefits of specific choices and reduce the uncertainty over their consequences. Furthermore, examples of family formation transitions lived by close network members suggest which is the shared normative framework within the network and on others' preferences. When "others" exercise some kind of "power" ascendancy on individual system of preferences, we call this process social influence. Social norms or social expectations about right and proper behaviour may modify individual preferences. Conforming to norms and expectations can be induced by the perceived costs of deviance - strong personal emotional reactions and subjective motivation to comply - or to explicit sanctioning. In this section we refer to that kind of influence that is parameterised as cost and benefit of social sanctioning /approval, while leaving social influence operating on the affective sphere to section 4.

The above mentioned social processes are more likely to have an effect on individual behaviours when a certain degree of uncertainty about the consequences of the behaviour exists, and when there are strong social expectations about what is the proper behaviour to be performed (Kohler et al. 2001). Both conditions, uncertainty and social expectations, seem to characterise fertility decisions (Pollack and Wachter 1975, Birg 1991, Stolzenberg and Waite 1977, Blossefeld and Huinink 1991, Heckhausen 1999), and particularly the decision context for Italian couples during the 1990 (Ciucci 1999, Billari and Lieftbroer 
2001). Both processes are likely to be more or less effective depending on the type of relationships involved as well as on the structure of personal relationship networks ${ }^{17}$.

Given the shift of childbearing decisions into the area of emotional indifference, decisions are likely to be dependent upon the social context of available information on opportunities and costs surrounding choices ${ }^{18}$, since this information defines the situation. For instance, the spacing preference for a short interval between two births has been shaped by previous observations in the following case:

Do you think to have them close?

Two year, one year and the half. It is better like that Why is it better?

Maybe it is harder at the beginning, but then the fact that they are together, they are each other's company, they make a group, and the group becomes stronger against the external world. It is a support against the environment. [...] My cousin, for instance, she had one sister, but she was 14 years younger, she had some difficulties, in the sense that they had problem with drugs as well. I may have seen this situation as due to the fact that she was alone with her problems, and she could not communicate these problems. The other cousins, who were all in couples if not 3 , did not have the same problems. So I deducted that this also (short interval between births) can help.

(Rossella - 35 years old - 0 children)

An efficient sequencing of events, if not anymore a "right one", is also an important parameter when deciding about fertility and therefore consequences of a "wrong" sequencing are also taken into account when: 
I have seen my friend who married just during the first year of University... it took her 12 years to finish studying, damn!! Finishing in 12 years would have meant dying for me! I mean, when you start you have to finish... because then once you have a family studying shifts to a second level, [...] and you never finish...even when you do, you do it as my friend did, with incredible effort...(Valeria, 1 child at the age of 35)

Learning takes place in a wider network of colleagues and neighbours, besides that of family members and friends. Experiences are not only observed, they are also object of conversations, of evaluation, and they are used as arguments for advises and warnings, as in the case of a too-long postponed first birth:

I remember at school, we were chatting with colleagues, children yes children no, there was one colleague married far 5 or 6 years, who could not have children, and he used to tell me: "look, be careful, do not wait too much, because if it happens what happened to me, after 5 years we do not manage to have a baby, you become crazy after 5 years! So start right now!" ...Then there was another one who had a child already who was saying: "try, it is not that evident that you become pregnant immediately...start trying"...so we tried and ... immediately!

(Laura -1 child at the age of 32)

Even when the reference for family choice does not coincide necessarily with one's own family of origin or with a more abstract model of traditional family, the reference force of those others with whom individual feels to share a similar "philosophy of life", loads learning with additional persuasive power: 
I have a friend who is like a sister to me, she is my age and she just had a baby. I was talking with her recently, we were talking about maternity. She had always been very similar to me - even if she chose the traditional marriage in the church - she had never been thinking about having babies before. When she found herself making this choice, and being happy about it, then we talked about it and she was advising me to try this experience...(Edda 35 years old - 0 children cohabiting)

The relevance of the single one-to-one relationship can be perceived by individuals involved themselves, while the impact of the tie structure, characteristic of the network, might not be easily recognisable from the individual point of view. Nevertheless, the size and the density of social networks shape an individual's social environment, and therefore affect the individual's opportunities for learning as well the weight of social norms, as we have discussed extensively elsewhere (Bernardi 2002). In addition to this immediate evidence of social interaction effects, consistent with the second model exposed in fig. $1 \mathrm{~b}$, we argue that together with explicitly providing information on opportunities and consequences of childbearing and childrearing choices, the influence of social networks extends on the non-cognitive level of internalised norms and emotions. This observation leads us directly to the next section, where we discuss the second line of interpretation.

\section{A second hypothesis}

\section{Interposing mechanisms}

A second line of interpretation justifies the inconsistency between the set of internalised norms (effectively oriented towards traditional models of transition to the adulthood) and 
consequent behaviour, without having to refer to the intermediate category of attitude. Rather, the inconsistency derives from positing the existence of a mechanism of interposition in the expectation-behaviour sequence, an interceptor mechanism which cannot be identified in the cognitive constructs generally taken into account (fig. 1b). It is as if "antagonist" mediators interposed themselves between decisions and the stratification of awareness upon which the system of preferences and expectations is based, as it happens in the processes of endocrine communication and cerebral synapses. These interceptors direct the individual towards this or that reaction on the basis of the way in which the individual's life events combine with his dispositions. Alternatively, they may even intercept every reaction, so that the individual seems to lack reactivity with no apparent reason.

We suggest that the crucial demographic choices of a life course are often "decisions not to choose" and that there is no necessary direct link between results and intentions. The rarefaction of procreative behaviour may then be interpreted as the result of a mechanism of interception between the preference system and the decisions. Analogous to the letting out a clutch, which makes it impossible to make a vehicle move forward, however desperately we may try to accelerate, the completion of the transition from preferences to action requires a release of control exercised by reason.

A theoretical category which well embodies the concept of crisis dispositions is that of security/insecurity of attachment of the child to a figure of reference, a theory that John Bowlby (1969) developed in his volumes Attachment and Loss. Anxious insecurity and avoidant insecurity are two basic mental dispositions which filter and translate individuals' value orientations into behaviour in the affective sphere, and which re-emerge in all critical 
choices. At the root of recent demographic behaviour in the Mediterranean regions, there may well be an anxious or avoidant dispositional state, capable of assuming the role of interceptors between desires and actions. This hypothesis is certainly not there to deny the existence of a broad range of structural factors - economic, sociological and anthropological - which are decisive in inducing the most recent generations to make self-delimiting choices in the reproductive field, and interpreted as "rational" choices. Here we would like to express the doubt into the self-sufficiency of some of the main neo-classical interpretations. Bowlby's theory of attachment (1969) provides us with a possible translation of the concept of "interceptor". An anxious or avoidant assumption of the caring instinct may also explain the recent changes in transition to the adult state and therefore also in fertility behaviour.

\section{Moods and dispositions and the Russel's circumplex}

On the broadest level human mental function is commonly divided into three basic faculties: cognition (thinking), conation (willing), and affect (feeling). Mood falls mainly inside the last of these categories. Parkinsons et al. (1996) draw up a list of some crucial differences between mood and emotion. Generally speaking, a mood accentuates the characteristics of an emotion: long-term duration, stable (sometimes built in function), weak, without a cause, not goal-oriented.

Nowlis and Nowlis (1956) attempted the first to implement techniques for mood measurement. Mapping the structure of affect was the aim of studies of word meaning on a psychometric methodology, known as semantic differential. Since 1977 J. A. Russell (1978, 1980, Russell and Mehrabian, 1977) has reviewed research employing multidimensional 
scaling and semantic differential procedures and suggested that the two dimensions of pleasantness (evaluation) and activation (activity) may fully account for intrinsic affective quality. Russell (1980) proposes that affect terms should be arranged in a circumplex representation (i.e. a two-dimensional circular structure) with axes corresponding to pleasantness and activation $^{19}$.

The desirability of tracing the map of dispositional states, gauging the position of semantic perception on the "pleasant-unpleasant" continuum is corroborated by the findings of Davitz (1969). He studied the similarities among the verbal description of emotional states, through a factor analysis conducted on 215 terms used to indicate three emotional experiences, and identified four main bipolar dimensions: of these, the two most stable were the level of activation (arousal) and the "hedonic" tone (pleasantness/unpleasantness) of the emotional state.

Which are the main effects of moods on the changing behaviour? The affect-priming model (Isen, 1984) suggests that mood states selectively activate information that is stored in memory. Bower (1983) argued that concepts are represented in the cognitive system as link-points or nodes in a lattice of interconnections. When a concept is activated, some of its activation is also transferred to nodes that are connected to it. An increase in activation makes the concept generally more accessible to retrieval processes and more likely to surface into consciousness. According to Bower, there are nodes in this semantic network that specifically represent pleasant and unpleasant affect, and the presence of either kind of mood involves some activation of the relevant node. This activation in turn spreads to the associated nodes, thus making the congruent information more available for processing. 
Thus, pleasant mood selectively triggers a chain of images and thoughts connected with positive experiences in the past or with pleasant meanings, which in turn may affect the way current information is processed.

This approach seems to be consistent with the 'interceptors' hypothesis: while a high 'hedonic tone' triggers links among cognitive nodes, 'crisis' moods or dispositions can defuse the same chains. It is not by chance that, classifying regulation strategies used to get out a 'bad' mood, Morris (1989) outlines 'cut-off' or 'avoidance' strategies aiming at managing mood or work on the affect itself (cognitive strategies as 'mentally switching off' or 'trying to put it out of mind', and behavioural strategies as distraction, removal or withdrawal).

\section{Measuring dispositions}

Theoretical speculations will be sustained by two different kinds of empirical evidence. The first evidence is based on the attempt to collect appropriate empirical indicators of some psychological dispositions connected to expectations related to family and fertility behaviours. In 1997 we attempted through an Italian survey to translate into empirical indicators certain value models and dispositional states which might be placed in relation to the system of expectations as regards family behaviour. Four dimensions of the pact of social and generational coexistence were measured:

a) a scale which measures the degree of "post-materialism" ${ }^{14}$, proposed by Inglehart (1993), based on Maslow's hierarchical theory of needs (1992); 
b) a scale of measurement of "familistic" orientation, which measures the priority assigned, in individual strategic decisions, to the collective good or - in contrast - to the "particular" good of the family to which one belongs ${ }^{15}$ (civicness vs. familism);

c) a scale - less usual in the analyses of opinion frames - of adherence to the pact of intergenerational solidarity or conversely of dissolution of this pact $^{16}$;

d) a scale of ethnocentrism, defined as the degree of intolerance towards excluded ways of living (e.g., drug rehabilitation centres, hostels for the mentally ill, special workshops for the disabled or travellers' communities).

Apart from these indicators of value models, the most ambitious attempt has been to measure the level of anxious insecurity and avoidant insecurity of an individual, founding categories of Bowlby's theory of imprinting, with a different procedure from that used by Bowlby's school. In order to do this, we used scales of semantic differential, starting from sets of key-words, in order to express the sensation of pleasantness/unpleasantness which they caused. A sample of 45 words of strong evocative potential, pre-selected for their representatives and stability of meaning, turned out to be sufficient for the construction of reliable psycho-cultural clusters (Micheli, 1999). The matrix of scores assigned to each respondent for each word, according to the pleasantness of the sensation evoked, was submitted to a principal component analysis. The co-ordinates on the semantic space may be a good approximation of the affective dimension.

Of the first four components, two may be traced back to the states of insecurity in Bowlby's theory. The first latent axis as per contribution to the total variance $(15.7 \%)$ represents a normative dimension, which distinguishes the states of emancipating (but 
anxious) self-regulation from those of hetero-directed regulation. The fourth latent axis according to the contribution to the total variance $(8.5 \%)$ represents a relational dimension, which distinguishes the states of trustfulness from those of avoidant insecurity.

The other two latent dimensions identified (marginal in the subsequent connections investigated here) are tied to the dispositional categories of

drive dependency, which distinguishes behaviour dominated by drives of order from other behaviour dominated by existential drives,

$>$ solidarity, which separates life-philosophies guided by utilitarian logic and competitiveness from others guided by solidarity and an instinct for care

The insertion of the two indicators of insecurity (anxious, avoidant) in the analytical models of expectations and behaviour formation turns out to be fairly useful. For the Abacus survey data, it emerges that the right number of children only exceeds replacement level from generation to generation among those with low levels of insecurity, either anxious or avoidant.

This finding also holds for each age group taken separately, and it is theoretically reasonable. In demographers' analyses ${ }^{18}$, anxious insecurity is often associated with the tendency to increase the value attributed to the risking of one's own decisions, and consequently to postpone them or contain their choice.

\section{TABLE 3 ABOUT HERE}

Table 3, with regression models applied to the data of the Abacus survey, is in line with this interpretation. Intention as regards the right number of children is influenced much less by the background variables, and much more by the dispositions of anxiety and avoidance, 
and this model turns out to be highly significant for the women interviewed. If we insert the actual number of children into the explanatory variables, this variable absorbs the model's entire contribution to the total variance: actual number of children and right number of children proceed in parallel, partly because of a selection effect and partly because of a mechanism of post factum rationalisation, such as those suggested in fig. 1b. But if we apply the same regression model to the actual number of children, the overall model is not significantly modified: the dispositional factors are still dominant compared to the structural ones and turn out, surprisingly, to be even more significant than the factor of age.

\section{TABLE 4 ABOUT HERE}

The crucial relevance of the two dimensions of insecurity in order to explain the dynamics of states of minds and attitudes is confirmed by the regression models for the value models concerning the pact of social and generational coexistence already discussed (table 4). Postfamilism and postmaterialism are significantly (p-value less than .001) and positively related with anxious insecurity (and negatively related with avoidant insecurity), whereas the degree of intolerance/ethnocentrism is strikingly related with avoidant insecurity.

\section{Excess of control ${ }^{20}$}

The qualitative data give further insights to the second line of interpretation, by adding to the survey evidenc the analysis of the narratives from which it is possible to infer the mood underlying the interviews. In Table 5 we summarised schematically the association between 
the mood typologies, the considerations on union and fertility transitions, and the affective and cognitive components in the narratives (Crittenden 1997)

Table 6 gives the distribution of the interviewees among the dispositions-family attitudes subcategories, where we find some interesting co-variations. On the one hand, those women classified as sure are more represented into the two groups of traditional familists and postfamilists, whose attitudes make their intentions concerning fertility and family choices less contingent on current opportunities. Anxious and avoiding moods are prevalent in the two remaining categories, of the individualist familists and the post-familists in transition (grey cells). On the other hand, anxiety seems to be associated more with the attitudes of the postfamilists in transition, while avoidance seems to be a characteristic of the individual familists.

\section{TABLE 5 ABOUT HERE}

In order to illustrate the essential and distinctive characteristics of these moods, we defined women's profiles according to the different family typologies. In this paper we concentrate on those two subgroups of women where the "intercepting moods" of anxiety and avoidance seem to be over-represented, which are the two typologies of attitudes towards family that we classified as unstable, i.e. the individualistic family and the post familist in transition. In fact, given the co-occurrences observed in table 2 , it seems plausible to hypothesise that: (a) the two 'stable' models (traditional and post-familist completed) minimise the risk of insecurity; (b) the post-familistic model in transition can temporarily produce anxiety, and consequently delay the main transitions to adulthood; (c) the individualistic family can be intended as a sort of secularised (individualistic) 'familism 
without familist solidarity', characterised by an-affective and deprived attachments. For these latter it is easier to manifest avoidance of any choice implying a transition to adulthood. These hypotheses are to be taken as a very temporary result that needs further investigation and more complete formulation in the near future.

\section{TABLE 6 ABOUT HERE}

In order to illustrate the essential and distinctive characteristics of these moods, we extract from the interviews the profile of particular women, declined according to different family typologies. In this paper we concentrate on the case of those two subgroups of women in which the "intercepting moods" of anxiety and avoidance seem to be over-represented, namely the two typologies of attitudes towards family that we classified as unstable ${ }^{21}$, that is the individualistic family and the post familist in transition.

\section{Case I: Tiziana, an anxious post familist in transition "I would like to..."}

Tiziana is 31 years old, has been married for seven years and lives in a small centre in the Alps valley. She is enrolled at University and works full time. She has no children. When asked the reason why they do not have children, she replied:

Because he was not relaxed about it (the husband), I did not feel like forcing him to bear responsibilities, since he is very responsible, he never dares, so he would have suffered a lot in having this responsibility and feeling relaxed about it,.... And then we decided when we feel good, we will see, we will think about having some, [...]I am always careful not to fall into the danger of being conditioned by what happens around me by what I see others are doing 
Reading the following extract there are at least three elements that respond to our category of anxious disposition: the desire of putting off the responsibility involved into having a child because one is "not ready", the necessity to exercise a responsible control over choices and to ignore social pressure, and the reference to a undefined future to think over delayed decisions ${ }^{22}$. All three elements are recurrent in the story she tells. When asked if it was then economic security what they were looking for as a pre-condition, Tiziana's answer switched to psychological security. She specifies that they were missing a feeling of being sure about themselves in the role of adults, and as a couple:

Being sure, psychologically relaxed. ... maybe we have hidden behind the idea of my and his professional security, but maybe it was really the fear...,[...] some immaturity or the very fear of bearing responsibilities. I do not know how to explain it, it is not really looking for economic security

The co-occurrence of the attractiveness of a family project for the couple and the feelings of personal inadequacy for the task that we indicated as the typical pattern signalling an anxious mood, is even better expressed by Marcella:

To me, even the idea of marrying, it has really ...I mean this step, even having other couples, knowing there were other people to rely on... Even marrying seemed to me something, 'oh mamma mia, let's wait'. I used to say ‘am I ready?'... And afterwards I have seen that... I mean really ready, you are never ready, as I am, I wasn't ready at 20 years old, I wasn't ready at 29”

Case II: Luisa, delay for an avoidant individualistic familist: "if it has to happen" 
Luisa is 38 at the moment of the interview, married for 18 years and living in a small centre well connected to the city of Milan. She had one child by her husband at age 30 after 10 years of marriage. She left home to get married relatively young after "only un annetto" of dating with her husband. She talk about it as something she did without "understanding":

I actually married really young, I was 20 , it was a choice ...I do not want to say forced, because after all, I had passed my $18^{\text {th }}$ birthday already, (she laughs) ... thinking back to it now actually, [...] I mean I have been lucky!... [...] you know, when you are 20 , you do not really have the head for starting a family, do you $[\ldots]$ I was thinking rather about having a job ... about living as many others were living

Contrary to Tiziana, Luisa describes the happening of major events in her life marriage, work related choices, the birth of the child - as a succession she hardly gave any direction to, minimising her own responsibility for the outcome ${ }^{23}$. She had never decided for or against having a child, as clearly expressed in the way she "contracepted" for such a long period

When I got pregnant I could not believe it, because I thougt I was not! (she laughs)... I never ... I was not looking for it, I was not using contraception, but you know, it was one of those situations when you say "ok after so much time it does not happen", I never really asked myself why [...] I had never been using contraception for ten years[...] we were always careful ! (laughs)... Maybe I was lucky! (laughs)... not that I was not happy afterwards but... [...] I was already 30 years old, I mean, I was not that young, I think it is a right age [...] 
not that I was really wishing to have a kid [...] I was always putting it off, even because I was really keen on the job I had...

Have you ever imagined staying childless?

No, really without not, like saying "no, I do not want any", no, not really, then I have been lucky cause it has arrived in that very moment...

Reading through the different extracts and the complete interview, it is worth noting how the cognitive and affective components referred to in table 3 as being typical for avoidance moods are recurrent in Luisa's expressions. A first clue is her frequent embarrassed laughing associated to the reporting of events that happened without her taking any active decision about or control over them, as when referring to her getting married at 18 or to discovering of being pregnant despite having "paid attention". A second cue is the inhibition of negative affective manifestation: she hints but minimises the negative reactions linked to the unexpected birth, preferring to list the attachment to her job, the lack of maternal support for childcare, the difficulties of the delivery, or the "things to do" after the birth. Many of her statements are expression of a double negative form as "not that I was not happy" and there is some attempt to insert the consequences of her non-choices in a sort of predictable and "normal" pattern ex post ("I thought I would have lived as many others" "I thought it could be a right age").

Luisa and Tiziana tell very different stories, with one common trait though: both of them haven't given birth to a child until age 30, despite a long lasting union (marriage). One of them actively chose to delay such an event, while the other did not decide anything specific about it. One was putting off the birth, the other was putting off the decision in favour of or against the birth. The paralysing effect of control overload - over the anticipated 
consequences of the event in one case and over the current situation in the other case seems to lead to the same outcome, the procrastination of the first birth.

\section{Disengaging the clutch (social influence and a spark effect)}

"Social models do not merely signal different norms, they affect how people view themselves and the possibilities in their lives" (Rachlinski 2000, p. 1551). Social models provided by "others" influence behaviour in two ways: a) by suggesting that the specific behaviour is or is not acceptable if someone else has engaged in it and having or not having encountered any socially induced penalty; and b) by showing what is possible, thereby changing what the observer believes accomplishable. The sense of personal (or self) "efficacy" concerning a certain behaviour or choice derives from the observation of others engaged in it. (Bandura 1986). In this section we will develop the second aspect and we will see how social influence may help in "disengaging the clutch", or switching off interposed moods. So far we have taken into account social influence only as directly affecting cognition. As we have stated previously, others can be source of emotional influence ${ }^{24}$ and therefore social interaction can affect moods and dispositions. There is evidence that births experienced by close network members can activate a childbearing decision-making process, because of the emotional proximity with the newborn. Similarly, they can provide a feeling of encouragement in facing what is considered to be 'such a responsibility'. Particularly, when family and fertility related transitions occur within a close-knit group of friends, they may produce a sort of 'anxiety reduction effect', since individuals overcome their sense of 
inadequacy, and perceive themselves to be ready, reducing the dissonance between intentions and behaviours.

Emotional arousal: in one third of the interviews, women stated that they had been induced to think about the possibility of having one or another child only after having been exposed to some other birth occurring in their network. Nothing else had really changed for the couple, neither their material situation nor their relationship, but the temptation derived by the newborn. Various reasons are given, such as having experienced a strong "attachment" to somebody else's new-born, or some form of jealousy, having been reassured that it is a natural feeling to start a family, having had a realistic impression of the presence of a child. Marcella, a 32 year old woman, married at 25, who had decided to wait some years before having children, and who declared to having "forgotten about it" later on, quotes a specific event as being the reason for considering childbearing again: the birth of a friend's child. The stress is on the physical sensations of being exposed to her friend's belly late in her pregnancy, observing the changes taking place in the house in preparation for the baby and then as a consequence of its presence:

"[...] I waited, but then there were a couple of friends who had one [the child] and so the idea came about: when they had this little girl, I thought, yes, there it is, we thought a bit about it, we took some time, we thought a bit about it and we decided.

And where were you meeting those friends at that time?

At work, I used to see them at work, she was a girl I had met at work, I hadn't seen her for a while and then we started meeting again. 
... And do you remember any conversation, something that made it come about? Well... No, it started, yeah, we used to meet, we used to talk about it. I found out about it when she was 5 months pregnant, you could see the belly, and then we started to daydream about it, and then when she had it, then the baby was there, you could see her, you could see the baby at home, you could see how the house changes...

What does change?

Well... I... when you entered their home, you used to see it. If you enter my house now...toys... things like that, the perfume, you could smell the new-born's smell. And after all I have always wanted them, so I chose...two" (Tecla).

In the above extract it is evident how to a vague desire for children ("I always wanted them") it does not go along with an equivalent intention to take a decision for or against this desire. If desires or intentions are left at a latent level (Jacobs 1995), explicit decisionmaking won't start until the latent desire is activated. Our argument here is that the activation mechanism could be provided, or anticipated, by social interaction, through all sorts of visual or psychological inputs, as in the example before and in the one that follows.

Anxiety reduction: The second mechanism is illustrated by the experience lived by Tecla, married for 4 years and with 2 children. Church-related circles have always played an important role in her life, before and after engagement and marriage. She refers to the stable group of friends in the local parish youth club as always having been a "reference point [punto di riferimento]". Despite the fact that she enrolled in and completed university studies, the secondary role of an education career in her life plan is discernible from the fact that she decided to marry and have her first child without having completed her degree, 
inverting the normally acceptable event sequence. She has always imagined she would have a family, but long refrained from it. The main concern was reconciling her ideal image of the family and her fear of not being able to form one herself, to fulfil the double role of wife and mother ${ }^{25}$. Therefore, she would have delayed her decision to marry forever, since for her having children is automatically part of the marriage ("if you decide to marry you have a certain maturity, you know it means having children").

\footnotetext{
"The desire to have a family was certainly there, always has been. I could not imagine I would not have had one. I simply thought it was too far off [...] Anyway with these friends we have a very tight relationship. So we saw how the relationship between them was. More than talking about it, we can say we had a preview experience, what they were doing, how they behaved. I mean, how they behaved before with no children and then with children. Then I thought it was a natural thing"
}

What is important to note here is that the declared delaying factors for marriage are not costs as economic difficulties or conflicting career plans, but rather the feeling of being inadequate, "not ready". The fear of failing in a highly valued task like having her own family is counteracted by the possibility of observing a close-knit group of friends (united by shared religious practices and convictions) with whom consequences could be observed and discussed.

Personally, it was very useful for me to observe the group, having the reference of the group, I mean, watching the people, even those who were older than me, living in a certain way, being happy. 
Once more, our two models allow us to interpret this case, alternatively. Uncertainty over change consequent to entering into parenthood and the irreversibility of the event could delay or inhibit the decision itself. According to first model, childbearing behaviours of peers provide a redefinition of what is possible, or, through subjective norms, might push individuals to express some kind of decision after a certain delay not to deviate and being excluded from the group. Alternatively, according to the second model, the supportive role played by social networks for taking an active decision, would be that of having displayed an encouraging example of bearing the "responsibility", of choosing to choose, removing the interceptor causing anxiety and finally matching expectations and behaviours.

\section{Conclusions and open questions.}

The previous pages summarise our effort to interpret lowest-low fertility with a comprehensive normative-affective approach. Moving from the common observation that achieved fertility is often lower than declared intentions; we arrived to two alternative theoretical explanations for such a gap. Our two hypotheses are alternative models to interpret the awkward coexistence of low fertility and familistic norms in Italy.

The first model assumes that delayed and foregone births are the consequence of a partial shift of family transition away from normative considerations. While family and fertility models are still normatively defined, cost-benefit considerations are applied to actual family choices. Social learning and social influence are fundamental mechanisms in this process since they shape costs definition and convey normative frameworks. In this perspective, where cognitive elements govern behaviour but not family models, costs are too high for the 
"familistic family" to come to existence (this is the case particularly for the two unstable family forms in section 2.3).

The second model relies on non-cognitive affective factors. The realisation that fertility would be hindered by the presence of general "negative" dispositions interposing their paralysing effect between intentions, again defined by the reference normative framework, and behaviours. Dispositions and moods may be modified by external inputs, as emotional influence is provided by social interaction. Both models apply normative-affective elements to work, but they suggest different causal chains conducting to the same behavioural outcome.

As expected, this paper ends with new questions and hypotheses rather than definitive answers with regards to our initial problem. Provided that dispositional state do act as indicated in conditioning demographic choices, the first question we need to answer is: what are the timing and the modalities for this change in dispositions to take place? In order to understand a change in behaviour, social practices or attitudes, it is not sufficient to seek a mere change in objective parameters or in their knowledge. We need equally (since strictly cognitive mechanisms fail to provide satisfactory interpretations of social change) to ask ourselves if and how a change in value models - or in dispositional states - might lie behind the change in social practices. But what critical events, individual or collective, might themselves explain these types of changes? And through which procedures? Despite that our focus in this paper was on the role that affective dispositions may play in the sequence intentions-behaviour, it is worth mentioning how one could identify the onset of a dispositional state at the population level. A dispositional state may originate as a reaction to 
a private as well as a collective event. The latter situation may produce consequences on the affective sphere of a relatively large part of the population and therefore the consequences on behaviour may be registered in changing trends at the macro level. A concrete example will help to clarify how in our view dispositions or moods can be one of the conditions for changes in cohort behaviour. The fall of the socialist regime in many eastern European countries has resulted in a dramatic change in fertility and family behaviour, with fertility rates dropping almost universally to unprecedented lowest low levels. Some scholars have explained such a change with the growing of the uncertainty with regards to the future of institutions and economy in these countries (Philipov 2000). The previous experience of a two-generation period of individual adaptation to the socialist system has to be put aside, as Heller (2000) powerfully depicts:

"Seemingly inconsequential issues are far from being inconsequential: how to get an education, how to get a job, how to find an apartment, how to go on vacation, how to visit a doctor, how to go to the hospital. Ten years ago, very abruptly, the unpopular but familiar world collapsed. Individuals had to learn new rules to new games. Some learn with ease, some with difficulty and others not at all" (Heller 2000, p.9). If the immediate behavioural response might be due to existing constraints to be overcome, such as finding employment and a house, the generalised feeling of instability might persist well beyond the material conditions ${ }^{26}$.

The second question emerging from the arguments presented in this paper can be formulated as follows: is the spread of interceptor mechanisms homogeneous? There is evidence that the processes of mass education did not bring about an homogenisation (either upward or downward) of the population. In contrast, Italy currently seems to be split in two, according to acculturation and relational capability. The undergoing change shows the more 
educated and integrated ones sailing under the flag of modernisation, post-familism and post-materialism. The less educated and less integrated one (scattered throughout the peninsula, and therefore also across the regions of the North), is subject to a different kind of modernisation, which combines persistent familistic values with manifestations of disruption in both interpersonal relationships and in intergenerational ones - ethnocentrism, intolerance, rescission of the pact between generations. As well, the two forms of insecurity are differently distributed in the two Italies. In all age groups, the more educated classes are characterised by a disposition of anxious self-regulation, while the less educated sections are characterised by a state of avoidant insecurity. Can we conclude that the current demographic trends in Italy are not the result of a single - however complex - process of social transformation, but rather the identical manifestation of two quite distinct processes taking place in two sociologically distinct Italies?

These questions are tentative directions in which to address future research to pursue the normative affective hypothesis we advanced in this $\operatorname{paper}^{27}$. The framework investigated so far seems to be internally consistent and rather efficient in explaining observed trends. More focused empirical research is needed in order to prove its strength or weakness. Possibly, in outlying the potentiality of the inclusion of affective factors and their social transmission, both intergenerational and across networks, we have given some input for pursuing such an empirical work. Any further consideration has to be suspended for the moment.

\section{References}

Ainsworth M.D.S. et al. (1978), Patterns of Attachment, Erlbaum, Hillsdale, NJ. 
Ajzen I., M. Fishbein (1980), Understanding attitudes and predicting behaviour, Englewood Cliffs, NJ: Prentice-Hall.

Bandura, A. (1986), Social Foundations of thought and action. A social cognitive theory, Prentice-Hall, New Jersey .

Banfield E. C. (1958), The moral basis of a backward society, New York, The Free Press.

Bernardi, L. (2002a), "L'influenza delle reti sociali nelle scelte di fecondità: il caso della Lombardia", in Micheli, G. A. (ed. by), Scenari demografici in Lombardia , Guerini Editore, Milano.

Bernardi, L. (2002b), The Personal Relationships and Reproductive Choices: Evidence from a Low Fertility Context (PhD Dissertation)

Billari F., G. A. Micheli (1999), "Social norms and demographic events in contemporary western societies: can we learn from Southern Europe?", paper presented at the Workshop for Social Interaction and Demographic Behaviour, Max Planck Institute for Demographic Research, Rostock.

Billari, F. and A. Lieftbroer (2001), "Should I stay or should I go? The impact of age norms on leaving home", Paper prepared for the 2001 Annual Meeting, Population Association of America, Washington, DC

Binswanger L. (1956), Drei Formen Missgluckten Daseins, Tubingen, Max Niemeyer Verlag (tr.it. Milano, Il Saggiatore, 1964).

Birg, H. (1991), "A biographic/demographic analysis of the relationship between fertility and occupational activity for women and married couples ", in Siegers, J., J. De JongGierveld, and E. Van Imhoff (ed. by), Female labour market behaviour and fertility, Springer-Verlag, Berlin.

Blossefeld, H.-P. and J. Huinink (1991), "Human capital investment or norms of role transition? How women's schooling and career affect the process of family formation ", American Journal of Sociology, 97:143-168.

Boeije, H. (2000), "Towards a purposeful approach to the constant comparative method in the analysis of qualitative interviews with couples ", [Paper presented at the Fifth International conference for social methodologists in social sciences 3-6 October in Cologne, Germany] 
Bower G.H. (1983), “Affect and cognition”, Philosophical Transactions of the Royal Society of London, series B, 302.

Bowlby J. (1969), Attachment and Loss. Vol. 1: Attachment, Basic Books, New York.

Broadbent D.E. (1971), Decision and stress, London, Academic Press.

Brown G. W., T. Harris (1978), Social Origins of Depression, London, Tavistock Publ.

Cicourel, A. (1974), Theory and method in a study of Argentinean fertility, John Wiley \& Sons, New York.

Ciucci, L. (1999), "Potenzialita' predittive delle aspettative di fecondita'", in De Sandre, P., A.

Pinnelli, and A. Santini (ed. by), Nuzialita' e fecondita' in trasformazione: percorsi e fattori del cambiamento, Il Mulino, Bologna.

Coale, A. (1973), "The demographic transition reconsidered", in IUSSP (ed.), Proceedings of the International Population Conference, Ordina, Liège.

Crittenden P.M. (1999), “A Dynamic-Maturational Approach to Mental Functioning” in Adulthood, trad. Attaccamento in età adulta, Cortina, Milano, 1999.

Dalla Zuanna, G. (2001), "The banquet of Aeolus. A familistic interpretation of Italy's lowest low fertility", Demographic Research, 4 (5).

Davitz, J. R. (1969). The language of emotion. New York: Academic Press.

Elster J. (1983), Sour grapes. Studies in the subversion of rationality, Cambridge, Cambridge University Press.

Elster J. (1999), Alchemies of the Mind. Rationality and the Emotions, Cambridge, Cambridge University Press.

Etzioni A. (1988), "Normative-affective factors: toward a new decision-making model", Journal of economic-Psychology, 9.

Fazio, R. (1990), "Multiple processes by which attitudes guide behaviour: the mode model as an integrative framework", Advances in Experimental Social Psychology, 23:75-109.

Festinger L. (1957), A Theory of Cognitive Dissonance, New York, Harper.

Fishbein M. and Ajzen I. (1975), Belief, attitude, intention and behaviour: an introduction to theory and research, Reading, MA: Addison-Wesley. 
Giddens A. (1992), The Transformation of Intimacy, Cambridge, Polity Press (it. tr. Bologna, 1995).

Heckausen J. (1999), Developmental Regulation in Adulthood. Age-normative and sociostructural constraints as adaptive challenges, Cambridge University Press

Heller, Agnes (2000), "Between Past and Future", in ANTOHI, Sorin and TISMANEANU, Vladimir (ed. by) Between Past and Future. The revolutions of 1989 and their aftermath, CEU Press, Budapest.

Janis, I. and L. Mann (1977), Decision Making. A psychological analysis of conflict, choice, and commitment, The Free Press, New York.

Kallegren, C., R. Reno, and R. Cialdini (2000), "A focus theory of normative conduct: when norms do and do not affect behaviour", Personality and Social Psychology Bulletin , 26 (8):1002-1012

Kohler, H.-P., F. Billari, and J. A. Ortega (2001), "Towards a theory of lowest-low fertility", Paper presented to the IUSSP General Conference, Salvador, August 2001

Korchin S. J. (1964), “Anxiety and cognition”, in C. Sheever ed., Cognition: theory, research, promise, New York, Harper \& Row.

Isen A.M. (1984), "Towards understanding the role of affect in cognition", in R.S. Wyer, T.K.Srull (eds), Handbook of social cognition, Erlbaum, Hillsdale.

Leibenstein H. (1981), "Economic decision, theory and human behaviour: a speculative essay", Population and Development Theory, 7, 3.

Lesthaeghe R., Vanderhoeft (1997), "Ready, willing and able", WP 1997-8, Vrije Universiteit Brussels.

Liebfroer A. (1999), Life-planning during young adulthood: do intentions about the timing of family-life events come true? Paper presented to the European Population Conference, The Hague, The Netherlands.

Maslow A. (1992), Motivazione e personalità, Armando, Roma.

Massey, D. (1996), "The age of extremes: Concentrated Affluence and poverty in the twenty-first century ", Demography, 33 (4):395-412.

Micheli G.A. (1999), Effetto generazione. Cinquant'anni di trasformazioni demografiche in 
Italia, Roma, Carocci.

Micheli G.A. (2000), "Kinship, family and social network. The anthropological embedment of fertility change in southern Europe", Demographic Research, 13.

Micheli G.A. (forthcoming), "On the verge of familistic interpretations. Familism, moods and other alchemies", In G. Dalla Zuanna, G. A. Micheli (eds), Familism and strtong familism in lowest low fertility countries, Kluwer, Groningen.

Mitchell, C. J. (ed. by) (1987), Cities, society, and social perception. A Central African perspective, Clarendon Press, Oxford.

Morris WN (1989), Mood: the frame of mind, New York, Springer-Verlag.

Myers S. (1997), Marital uncertainty and childbearing, Social Forces, 75.

Nowlis V, H. Nowlis (1956), "The description and analysis of mood", Annals of the New York Academy of Psychology, 65.

Palomba, R. (1995), "Italy: the invisible change", in Palomba, R. and H. Moors (ed. by), Population, Family and welfare, Clarendon Press, Oxford.

Parkinson B., P. Totterdell, R. Briner, S. Reynolds (1996), Changing moods: the psychology of mood and mood regulation, London, Longman.

Pollak R. and M. L. Wachter (1975), "The relevance of the household production function and its implications for the allocation of time ", The Journal of Political Economy, Vol. 83 (2):255-278.

Rachlinski, J. (2000), "The limits of social norms", Chicago Kent Law Review, 4:1537-1561

Rogers E. and D.M. Kincaid (1981), Communication Networks: toward a new paradigm for research, Free Press, New York.

Russell J.A. (1978), "Evidence of convergent validity on the dimensions of affect", Journal of Personality and Social Psychology, 36.

Russell J.A. (1980), “A circumplex model of affect”, Journal of Personality and Social Psychology, 39.

Russel J.A. and A. Mehrabian (1977), "Evidence for a three-factor theory of emotions", Journal of Research in Personality, 11.

Stolzenberg, R. and L. Waite (1977), "Age, fertility expectations and plans for employment", American Sociological Review, 42 (5):769-783. 
${ }^{1}$ In Leibenstein's inert area model (Leibenstein, 1981) as well as in Fazio's mode model of (Fazio,1990) cognitive processes play a secondary role. Rational decision-making processes are rarely activated compared with the more frequent application of routinised behaviour, which is inertia-defined in the first model and attitude-driven in the second model. Since decision processes are costly for the individual only, a high motivation to engage in them would make behaviour dependent upon conscious choice.

${ }^{2}$ Etzioni's normative-affective decision-making model affirms, along the same lines, that certain considerations are either so morally unthinkable or conceptually irrelevant that they are blocked from conscious consideration (Etzioni 1992).

${ }^{3}$ It has been noted that in pre-transition society, sub-populations controlled fertility through alternative strategies such as avoiding marriage (Wilson and Airey 1999). What we mean here is that contraceptive acceptance made it possible to avoid childbearing without having to change many other life plans.

${ }^{4}$ In a recent study on voluntary childless couples in Britain the authors distinguish men and women who claimed never to have taken any decision about childbearing as "ambivalent". They had not put off childbearing until they remained childless, but they rather put off thinking about the possibility of becoming parents or not (McAllister and Clarke 1998).

${ }^{5}$ According to Janis and Mann (1977) when decision-making produces anxiety or emotional strain, individual behaviour may fall into a defective pattern. The authors indicate four of them: 1) inertial, which is persisting in the current behaviour; 2) shift to a new course of action; 3) defensive avoidance; 4) anxiety increasing control.

${ }^{6}$ According to Etzioni (1986), there are at least three ways in which values and emotions interact with rational decisionmaking: (1) Exclusion: emotional reactions prevent the use of logical empirical consideration/holding specific values exposes one to selective information. (2) Enclosure: specific zones of emotional indifference - defined as legitimate indifference zones - are set by normative-affective factors. Values define the order of priority for goals to be pursued by rational decision-making. (3) Intrusion: normative-affective factors cut short the rational process in many ways: a) each step in the process of decision making could be cut short; individuals collect numerous facts but under-analyse them and 'jump' to conclusions; c) high stress induces rigidity, reduces attention and tolerance for ambiguity (on this aspect see also Korchin 1964).

${ }^{7}$ Leibnstein elaborates on the concept of passive decision-making involved in routine behaviour, when individuals do not engage in rational calculation, but rather behave within an holding pattern. Because of the effort required by active decision-making, most behaviour falls into an inert area insulated from external events (Leibnstein, 1988). In this framework, active decision-making arises only when a change in the external conditions causes a shift beyond the lower or upper bounds of the inert area. In this case a sufficient stimulus arises for engaging in active decision-making.

8 According to Yerkes-Dodson Law (1908) effectiveness increases until a threshold level decreases beyond it, as stress continues to increase. Similarly, decision-making effectiveness increases with environmental pressure. When environmental pressure is low, individuals may follow habitual or conventional behaviour of some sort. When environmental pressure rises active decision-making is triggered. At first, individuals may engage in rational reaction to the new situation. Though, were pressure to increases even further sensible behaviour may be dropped altogether. The emotions related to very high degrees of stress influence the result so that effectiveness declines (Broadbent, 1971).

${ }^{9}$ Myers (1997) finds that the couples "who get along well", whose marital relationship is more certain, who have more common ties, who are longer married, who are geographically more stable, are more likely to have an additional child". Therefore he concludes that childbirth is rather a consequence of partners' investment on each other rather than a way of reducing marital uncertainty or increasing marital solidarity.

${ }^{10}$ How have these moods come about? Micheli (forthcoming) advances the hypothesis that a two-step mechanism has been at work in the recent past: on the one hand cumulating and lagged emergencies within the life course, on the other hand a disturbed imprinting between generations transforming the intergenerational transmission from a monotropist culture to a system of multiple attachments. The security-insecurity dimension elaborated by John Bowlby is fundamental in the explanation: anxiety and avoidance moods-as well as depressive syndromes - filter the value orientations which are present in the individual affective sphere, intercepting (in this case blocking) the realisation of consequent behaviours. Obviously, these are only tentative interpretations, which need robust research designs in order to be tested.

${ }^{11}$ There seems to be a paradox in the fact that in contexts where the institution of marriage, as an expression of the traditional family formation, and familistic values are confirmed, at the same time the pillar of the family, reproduction, seems to be endangered by the actual behaviour (Micheli 2000).

${ }^{12}$ This sampling procedure allowed to identify the specific selection of the small qualitative sample by means of a comparison with the larger survey sample, representative of women in the region under study. Analysis show that the women interviewed are likely to have quoted on average a relatively larger network of important others and to have a slightly higher family size (cfr. Bernardi $2002 \mathrm{~b}$ for details). 
${ }^{13}$ For the theory to be confirmed (or falsified) we would need survey data containing information on individual networks and ties characteristics and about the content related to family formation of interactions with each member of the network.

${ }^{14}$ For stable patterns we mean simply patterns that are not yet or no longer in transition.

${ }^{15}$ The validity of these categories is independent from their prevalence in the specific dataset under study since the sample is not representative of Italian women. Rather they assume validity when it is shown that they stand for the regularity with which certain concepts are applied jointly (Mitchell 1987).

${ }^{16}$ We exclude from the definition of social influence all forms of coercive power.

${ }^{17}$ Social influence on individual preferences and the normative power of others seem to grow with intensity of the relationship. The frequency of contacts, the amount of time spent together, the level of intimacy, the exchange of material and psychological support among people, define the degree of intensity of their relationship. For instance the salience of the relationship is often associated to the extent of social influence (Kallegren et al. 2000)

${ }^{18}$ We will give examples of social learning about opportunity and costs and not of social influence, to be understood in the sense specified above. We address the interested reader to Bernardi (2002b) for further documentation on social influence in shaping cost benefit balance of specific fertility choices.

${ }_{19}$ Many theorists have assumed that intermediate levels of arousal are experienced as affectively neutral. Also in Parsons (1957), one of the five pattern variables consists of the axis "immediate gratification (affectivity) - deferred gratification (affective neutrality)".

${ }^{14}$ This places individuals on a scale of priority of needs which ranges from the level of primary needs, or survival, through those material needs of stable social organisation, to the so-called "post-material" needs of self-expression and selffulfilment. The Abacus survey took up the reduced version of the set of items used by Inglehart, in order to construct a fairly broad index. The reduced set used by Inglehart is the following: "There has been much talk in recent years of what the goals of this country should be. Which of the following questions do you regard as being first, second and third in order of importance? a) Maintaining the country's law and order; b) Combating inflation; c) Giving people more decision-making power; d) Protecting freedom of speech". As is fairly obvious, priorities a) and b) are of a material order, while c) and d) are "post-material". The order indicated by the respondents also features a greater propensity towards one or other of the two levels.

${ }^{15}$ Let us consider as a proxy of familism a composite indicator based on two items: a) "we are responsible first towards family and children and then towards the community"; and b) "love towards family and children does not justify acting against the interests of the community". Let us define as "familistic attitude" the priority given to the good of the family compared to that of the community (in accordance with item a) and as "post-familistic" the inversion of that priority (in accordance with item b)).

${ }^{16}$ The degree of adherence-rejection of the intergenerational pact has been measured by two items (opposite in meaning) which make reference to the obligations of children towards parents and vice versa: a) "It is right for children to make sacrifices and have elderly parents living with them"; b)"Parents have a right to their own lives, without making sacrifices for their children".

18 "The decline in Italian fertility appears linked to (if not directly caused by) the high value attributed to motherhood" In fact, this decline, far from being associated with the downplaying of reproductive and caring activities, "the wellbeing of children and total devotion to them are seen as the greatest values in life. The fall in the birth rate in Italy is taking place without any simultaneous increase in marriages without children or in cohabitation. The fall in the number of children per woman (...) may well explained by the hypothesis of an "improved quality" of children. Italian parents want to be better parents for a lower number of children" (Palomba, 1995).

${ }^{20}$ The expression 'excess of control' makes reference to the more commonly used term of 'information overload', used to define those situations in which a confusing excess of available information produces, among other effects, anxiety and poor decision-making

${ }^{21}$ Obviously most interviewees show traits that can not be re-conducted to a single category, but still in almost the totality of the cases, the majority of their attitudes, opinions and behaviours as well as their narratives makes it possible to place them in one or the other. Those presented as ideal type are no exception, but they most clearly illustrate the concepts laid out in out analysis.

${ }^{22}$ Tiziana intends to take care of her future child herself, once there will be one, despite she would have the opportunity to be helped by her family of origin. She expresses concerns over the necessity for a correct education which can't be provided by grandparents.

${ }^{23}$ Her second main step to family formation, the birth of her child after ten years of marriage, also is reported as the result of a set of coincidence: the firm she was working for closed down and she discovered at the same time that she was pregnant.

${ }^{24}$ A similar effect is applied in studies concerned with the individual internalisation of violence in environments where violence is endemic: "violence is more than a socially learned reaction that one can set aside whenever the situation 
warrants. Repeated exposure to a high level of danger and physical violence wire emotional predisposition to rage and violence" (Massey 1996)

${ }^{25}$ The fear of not being able to face the educational responsibility involved in raising a child was indicated as being one of the factors conditioning the decision to have children by 18 of the 54 women interviewed.

${ }^{26}$ For further elaboration on this point cfr. Micheli (forthcoming)

${ }^{27}$ For further theoretical development on the concluding open questions, see Micheli (forthcoming) 
Social network:

social norms and social influence

DECLARED intentions of parenting

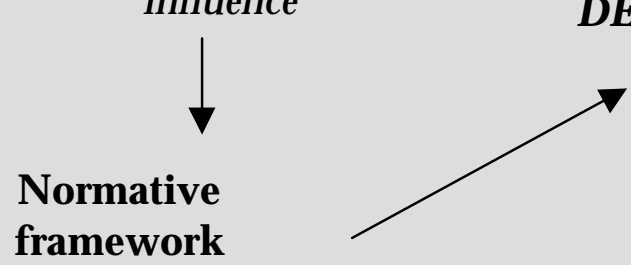

PERCEIVED

costs

are high

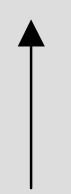

Social network:

ystem of beliefs and

social learning

$$
\begin{gathered}
\text { Behavior } \\
\text { (putting off / rejecting } \\
\text { transitions) }
\end{gathered}
$$

\section{Social network:}

social norms and social

influence

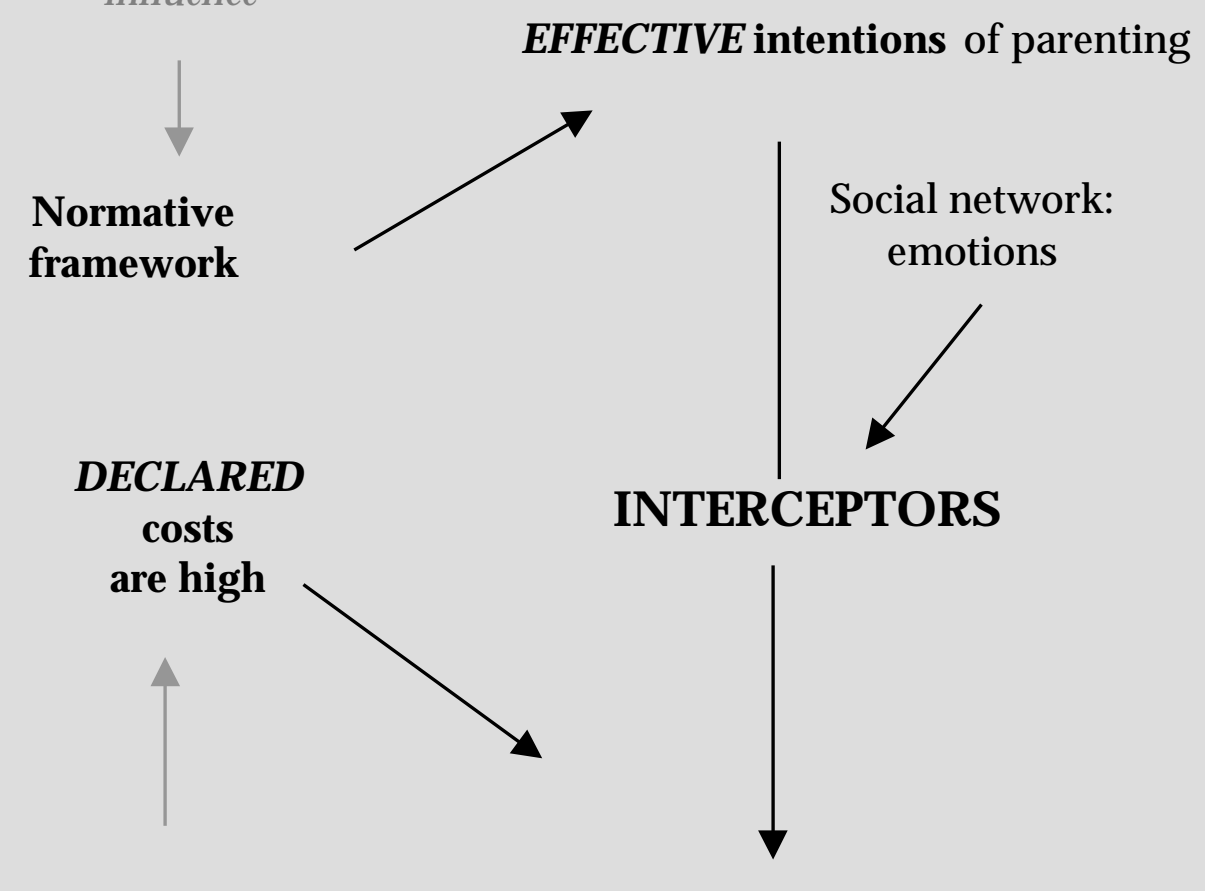

Social network:

system of beliefs and

social learning

Behavior

(putting off / rejecting

transitions) 


\begin{tabular}{|c|c|c|c|c|}
\hline $\begin{array}{l}\text { family } \\
\text { types }\end{array}$ & topics & nion (and children) & Woman role & Attitudes towards costs of childrearing \\
\hline 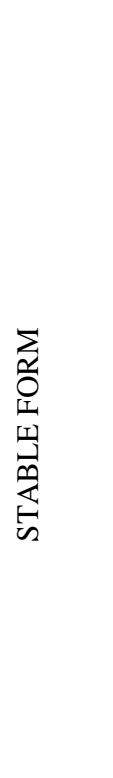 & 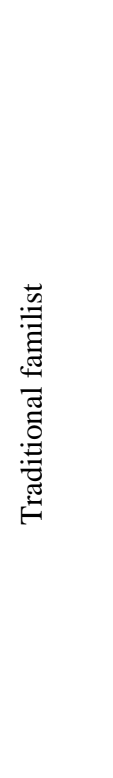 & $\begin{array}{l}\text { Package children marriage } \\
\text { "According to me, there is no marriage without } \\
\text { children... those who choose that make a mistake } \\
\text { from the beginning, a mistake, because it's a } \\
\text { nonsense choice, it is like saying "I become a } \\
\text { priest but I do not celebrate the communion", I } \\
\text { mean... it does not follow up spontaneously" }\end{array}$ & $\begin{array}{l}\text { Childcare } \\
\text { "In my opinion children have to be ...raised by parents, therefore I } \\
\text { do not like the idea of 'parking' them at their grandparents' place, or } \\
\text { letting the grandparents coming and do babysitting... it is a matter of } \\
\text { principle" } \\
\text { Working mother } \\
\text { "all these mother going to work just to have some luxury, just for the } \\
\text { money, to be independent.... they do not realise. . I understand a } \\
\text { woman going to work because she needs the salary but when she } \\
\text { talks se says she would rather stay at home, I can understand that..." } \\
\text { Built in conflict } \\
\text { "well I say that the 'old-fashion mother' she knew how to play the } \\
\text { mother and the wife now they know how to do the manager or the } \\
\text { emancipated women, sure, but if you are outside you can't be inside } \\
\text { so you need somebody to take care of your children, somebody who } \\
\text { thinks for you cause you can't be simultaneously in two places: either } \\
\text { you work or you stay at home" } \\
\text { The good mother } \\
\text { "I do not give credit to those who say 'we are optimal workers and } \\
\text { optimal mothers', I guess they might be good workers, as far as good } \\
\text { mothers ...I prefer to be what I consider an optimal mother..." }\end{array}$ & $\begin{array}{l}\text { Economic costs } \\
\text { "eh... I call them 'couples that makes very brave } \\
\text { choices' ... Economically brave... my parents } \\
\text { did this choice, when I was born my mother } \\
\text { stopped working, and I thank her and will thank } \\
\text { her all my life through, because she grew me up } \\
\text { herself, and it is a totally different thing" } \\
\text { Costs are given (solution is balancing) } \\
\text { "I am not, I do not need objects, things, I need... } \\
\text { seeing at my children when they go out and } \\
\text { looking at their faces when they come back, } \\
\text { trying to figure out if there are problems, if } \\
\text { everything was fine at school ...I need this kind } \\
\text { of things" } \\
\text { "I couldn't wait for marrying and having } \\
\text { children, ...having a child for me was an } \\
\text { immense joy, even though it has been also an } \\
\text { incredible tiring thing... in some respects... but } \\
\text { it is such a satisfaction". }\end{array}$ \\
\hline 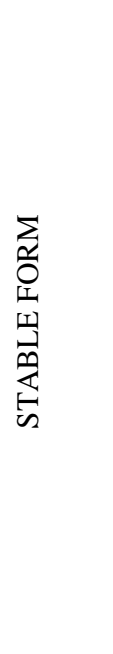 & 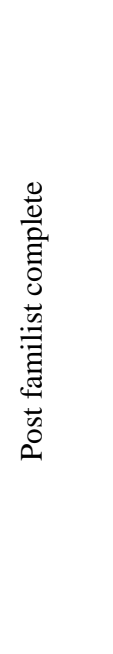 & $\begin{array}{l}\text { Parenthood as a possibility } \\
\text { "after all we are quite autonomous persons. We } \\
\text { have many interests pretty much separated, Iso that } \\
\text { couple life was not the only focal point in our life, } \\
\text { therefore we could always believe one other.... } \\
\text { Even if children would not have arrived at that } \\
\text { time I was not feeling as a drama. At the beginning } \\
\text { I really did not want them. I mean I did not want } \\
\text { them at that stage, not that I did not want them at } \\
\text { all. It came about little by little.... without any clear } \\
\text { cut decision. It has been a very gradual matter" }\end{array}$ & $\begin{array}{l}\text { Stress on self realisation } \\
\text { "Even now, when I need to update (professionally) myself, I have to } \\
\text { lock myself, I mean my husband does not exist anymore, nor my } \\
\text { studio, nor my child, nor anything else but for the reading ..." } \\
\text { Stress on individual identity } \\
\text { "When I socialise, I leave my children at home honestly. Rather I go } \\
\text { out for them with them. But if I go out for myself then I leave them at } \\
\text { home. In this case either there is a baby-sitter or the grandmothers... } \\
\text { I am not the kind of mother that puts an ocean between her and her } \\
\text { children, definitively not. But I have never given up to my own } \\
\text { spaces" } \\
\text { No conflict between roles } \\
\text { "I think that when a woman is satisfied in her professional and social } \\
\text { life, she feels also better with her child, she can live maternity in a } \\
\text { different way, than a stressed out mother, for which every little thing } \\
\text { is unbearable, sometimes you need to disconnect, create your own } \\
\text { areas...to have a broader view, I think... also the child profit of that } \\
\text { after all" }\end{array}$ & $\begin{array}{l}\text { Well-being of the couple } \\
\text { "we have been waiting for it with joy, with } \\
\text { strength and with joy really,... if I had to go } \\
\text { somewhere I would bring my own little "hand- } \\
\text { luggage' (the child itself)... there was a moment } \\
\text { that ...that ... we felt this exigency, there was an } \\
\text { emptiness, ... the couple can be unified only } \\
\text { from the birth of a child" } \\
\text { Costs are given (solution is weaving) } \\
\text { "he understands (the husband) that there are days } \\
\text { I go away, or tha I go and see the Biennale, } 2 \text { or } 3 \\
\text { days, sometimes I bring my child, if he can't I go } \\
\text { alone ...I never gave up since I am married to go } \\
\text { and see the Biennale in Venice, when I was } \\
\text { pregnant, then with the child in the stroller, then } \\
\text { on his own feet...last year we went the } 3 \text { of us } \\
\text { together..." }\end{array}$ \\
\hline
\end{tabular}




\begin{tabular}{|c|c|c|c|c|}
\hline $\begin{array}{l}\text { family } \\
\text { types }\end{array}$ & topics & Union (and children) & Woman role & Attitudes towards costs of childrearing \\
\hline  & 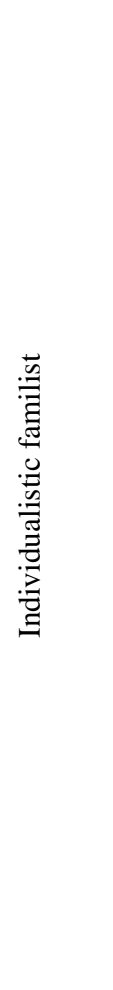 & $\begin{array}{l}\text { Married union as a social obligation } \\
\text { "..for it is a bound...ok, you marry and all the rest, } \\
\text { but even if we would have cohabit it was the same, } \\
\text { it wouldn't have changed... ... Married, in the } \\
\text { church, the ritual... well it was more for them (the } \\
\text { parents) than anything else..." } \\
\text { "everybody makes his/her own choices, I mean, I } \\
\text { do not mind, even if hear somebody saying "I do } \\
\text { not want children", I mean, why judging her? I } \\
\text { mean, anybody can choose his/her own life, I } \\
\text { chose to have only one child, you can even say I } \\
\text { am selfish..." }\end{array}$ & $\begin{array}{l}\text { Managing individual life } \\
\text { "I have a good job and won't' quit it....I mean my job is really a } \\
\text { lively job, there is no routine, it brings satisfaction satisfactions and } \\
\text { for now I won't leave it" } \\
\text { Investing in childrearing } \\
\text { "I think children feel good where they receive inputs, with their } \\
\text { father, their mother and father and stop. But then, since I decided to } \\
\text { work, rather than with a granny better for them in a kindergarten, or } \\
\text { with a young babysitter to bring them around, showing them the } \\
\text { world, educating them..." } \\
\text { "it is not so important the quantity of time you give to your child but } \\
\text { the quality ...I may be with them half of the time of the mother who } \\
\text { stays at home, but when I am with them I try to be with them" } \\
\text { Built-in conflict } \\
\text { "my sister was born to be a mother, the person who is inclined } \\
\text { towards freedom it is me in the family, my younger sister is much } \\
\text { more a mother than a woman... I care about my freedom, going out } \\
\text { with my friends from time to time ... to the cinema, I still do it...I do } \\
\text { not think I abandon my daughter when I go shopping" }\end{array}$ & $\begin{array}{l}\text { Other priorities } \\
\text { "we waited to have the first child } 5 \text { years because } \\
\text { we bought this house and I did not want to have } \\
\text { children unless I had the financial security, we } \\
\text { had just started the mortgage, I said we will have } \\
\text { a child when there are no other debts..., one can } \\
\text { say " ok I do not care about that I stay at home... } \\
\text { I did not" } \\
\text { Child for the self-fulfilment of the couple only } \\
\text { "yes, well, I did not have any idea about it } \\
\text { (having children), I mean I was not interested, I } \\
\text { mean, even if they were not coming, I mean ...I } \\
\text { was fine until I have noticed that me and him, } \\
\text { always the same things, we did not have anything } \\
\text { to do anymore, there was nothing, we were here } \\
\text { in the evening the two of us, I mean it was } \\
\text { getting boring... and then I decided, but before I } \\
\text { was feeling fine, I mean I liked being here and } \\
\text { doing nothing, no problem, I could go wherever I } \\
\text { wanted to... } \\
\text { until I got enough of it, reading was boring, } \\
\text { watching TV was boring, housekeeping was } \\
\text { boring... there was a point I said well, we do not } \\
\text { know anymore what to do , where to go, and then } \\
\text { Federica was born and there was even too much } \\
\text { to do!" }\end{array}$ \\
\hline 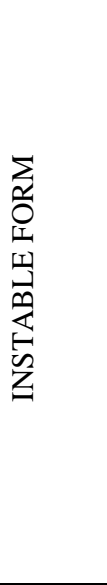 & 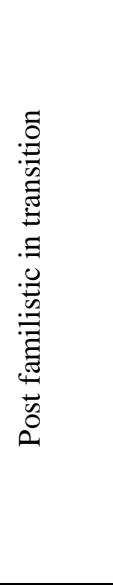 & $\begin{array}{l}\text { Motherhood as a meaningful transition } \\
\text { "the important thing is to feel good with a person } \\
\text { you love, you have chosen, with whom spending } \\
\text { your life, so... this is the family....anyway you do } \\
\text { not have children just to have someone one day in } \\
\text { the future, ...I was told I am very selfish, but I } \\
\text { think you need as mush as egoism to bring another } \\
\text { person to this world, because you can't do it just } \\
\text { because one day you could want something back } \\
\text { from this child ...." }\end{array}$ & $\begin{array}{l}\text { Ready for investing in childbearing } \\
\text { "what I wanted to do I did it, now I am ready for another kind of } \\
\text { project, even if I had to give up job completely... well I would rather } \\
\text { not ... I mean, I know children are a big effort but once they go to } \\
\text { school, still they are an effort but not that much. } \\
\text { Differentiating woman from mother } \\
\text { I would like to avoid to lock myself into the house, I prefer to do my } \\
\text { job, maybe } 3 \text { days a week rather than } 6 \text {, even better, because I really } \\
\text { feel the necessity to keep myself updated on what happens, of being } \\
\text { informed, I wouldn't like to concentrate my work only on children } \\
\text { food or little red asses, maybe for a short time, but then not..." }\end{array}$ & $\begin{array}{l}\text { Balancing costs and monitoring choices } \\
\text { "well, now we are a bit calmer, economically- } \\
\text { wise, the fact of being married... I had no doubt, } \\
\text { otherwise I wouldn't marry! (RS) But anyway, } \\
\text { everything is calmer and maybe we are ready as } \\
\text { well, my husband's job, now he has his own } \\
\text { business that walks all alone, I am more relaxed } \\
\text { so even the idea to have a child now... " } \\
\text { References to renounces } \\
\text { "maybe I feel the time given to me is almost } \\
\text { over, more than the real will to have a child ... I } \\
\text { mean, some wish is there, cause if I had it now I } \\
\text { would be happy... having it, the first years, } \\
\text { changing him, not sleeping at night and all the } \\
\text { rest hmmm... I am a bit less keen on (RS) ... but } \\
\text { anyway you know it is like that so..." }\end{array}$ \\
\hline
\end{tabular}


Table 3 - Different proprieties of moods and emotions (Parkinson, 1996)

\begin{tabular}{|l|l|l|}
\hline & Mood & Emotion \\
\hline Duration & Relatively long-term & Relatively short-term \\
\hline Time pattern & Gradual onset, continuous & Rapid onset, episodic \\
\hline Intensity & Relatively weak & Relatively strong \\
\hline Function & Provides information about current state of self & Provides information on current state of situation \\
\hline Causation & Not caused by specific event & Caused by specific event \\
\hline Directness & Unfocused & Takes specific object \\
\hline
\end{tabular}


Table 4 - Abacus survey: measurement of Varimax four principal components (15 cluster of words centred on dispositional states, contribution to the total variance $=45 \%$ )

\begin{tabular}{|l|l|l|l|}
\hline Factor & $\begin{array}{l}\text { Contribution to } \\
\text { the total variance }\end{array}$ & $\begin{array}{l}\text { Cluster of words centred on dispositional } \\
\text { states on the positive axis }\end{array}$ & $\begin{array}{l}\text { Clusters of words centred on } \\
\text { dispositional states on the negative axis }\end{array}$ \\
\hline $\begin{array}{l}\text { I } \\
\text { Normative } \\
\text { dimension }\end{array}$ & $15,7 \%$ & $\begin{array}{l}\text { elusion (evasion, irony, anti-conformism) } \\
\text { reversibility (flexibility, lightness, change) } \\
\text { rationality (logic, reason, construct) }\end{array}$ & $\begin{array}{l}\text { rituality (faith, sacred, ceremony) } \\
\text { family (marriage, home, faithfulness) } \\
\text { conservatism (hero, law, moral) }\end{array}$ \\
\hline $\begin{array}{l}\text { II } \\
\text { Drive } \\
\text { dependency }\end{array}$ & $11,0 \%$ & $\begin{array}{l}\text { emotionality (dream, music, moon) } \\
\text { anguish (labyrinth, empty, cry) } \\
\text { sensuality (sensual, intimacy, skin) }\end{array}$ & $\begin{array}{l}\text { rationality (logic, reason, construct) } \\
\text { conservatism (hero, law, moral) }\end{array}$ \\
\hline $\begin{array}{l}\text { III } \\
\text { Solidarity } \\
\text { dimension }\end{array}$ & $9,4 \%$ & $\begin{array}{l}\text { care (maternal, protect, cure) } \\
\text { attachment (nest, tenderness, friendship) }\end{array}$ & $\begin{array}{l}\text { aggression (quick, challenge, ambition) } \\
\text { utilitarianism (property, money, wealth) }\end{array}$ \\
\hline $\begin{array}{l}\text { IV } \\
\text { Relational } \\
\text { Dimension }\end{array}$ & $8,5 \%$ & $\begin{array}{l}\text { avoidance (criticise, rigid, diffidence) } \\
\text { utilitarianism (property, money, wealth) }\end{array}$ & $\begin{array}{l}\text { transcendence (infinite, soul, eternal) } \\
\text { rituality (faith, sacred, ceremony) }\end{array}$ \\
\hline
\end{tabular}


Tab. 5 - Abacus survey: regression for the right number of children and for the actual number of children by gender and various intermediate variables (interviewed 20-49 years old)

\begin{tabular}{|c|c|c|c|c|c|c|c|c|c|c|c|c|}
\hline & \multicolumn{6}{|c|}{ right number of children } & \multicolumn{6}{|c|}{ actual number of children } \\
\hline & \multicolumn{2}{|c|}{$M+F$} & \multicolumn{2}{|r|}{$\mathbf{M}$} & \multicolumn{2}{|r|}{$\mathbf{F}$} & \multicolumn{2}{|r|}{$\mathbf{M}+\mathrm{F}$} & \multicolumn{2}{|c|}{$\mathbf{M}$} & \multicolumn{2}{|c|}{$\mathbf{F}$} \\
\hline & $\beta$ & $\mathbf{t}$ & $\beta$ & $\mathbf{t}$ & $\beta$ & $\mathbf{t}$ & $\beta$ & $\mathbf{t}$ & $\beta$ & $\mathbf{t}$ & $\beta$ & $\mathbf{t}$ \\
\hline Size of network & +.065 & 1.799 & +.076 & 1.180 & +.060 & 1.358 & +.052 & 1.012 & +.078 & 0.849 & +.019 & 0.297 \\
\hline Age & -.002 & 0.054 & -.018 & 0.274 & +.011 & 0.253 & +.082 & 1.574 & +.118 & 1.330 & +.074 & 1.164 \\
\hline $\begin{array}{l}\text { Anxious } \\
\text { insecurity }\end{array}$ & -.098 & $2.716^{\star}$ & -.042 & 0.652 & -.120 & $2.726^{*}$ & -.189 & $3.628^{\star \star}$ & -.178 & 1.919 & -.201 & $3.136^{\star}$ \\
\hline $\begin{array}{l}\text { Avoidant } \\
\text { insecurity }\end{array}$ & -.126 & $3.521^{\star \star}$ & -.124 & $1.963^{\star}$ & -.115 & $2.614^{*}$ & -.152 & $2.925^{\star}$ & -.289 & $3.209^{\star}$ & -.072 & 1.119 \\
\hline Size of city & +.087 & 2.390 & +.008 & 0.128 & +.124 & $2.760^{\star}$ & +.057 & 1.067 & +.057 & 0.632 & +.061 & 0.912 \\
\hline Education & +.015 & 0.406 & -.059 & 0.894 & +.050 & 1.075 & -.002 & 0.043 & +.186 & $2.000^{\star}$ & -.088 & 1.326 \\
\hline Significance (F) & & $4.688^{* *}$ & & 1.220 & & $4.368^{* *}$ & & $4.174^{* \star \star}$ & & $3.975^{\star}$ & & 2.315 \\
\hline $\mathbf{N}$ & & 767 & & 258 & & 508 & & 359 & & 115 & & 243 \\
\hline
\end{tabular}

Glossary *P-value $<.01 ; * * \mathrm{P}$-value $<.001$. 
Table 6 - Abacus survey: regression for four models of value (ethnocentrism, postmaterialism, rescission of intergenerational solidarity pact, postfamilism) by various intermediate variables (interviewed 20-49 years old)

\begin{tabular}{|c|c|c|c|c|c|c|c|c|}
\hline & \multicolumn{2}{|c|}{ ethnocentrism } & \multicolumn{2}{|c|}{ postmaterialism } & \multicolumn{2}{|c|}{$\begin{array}{l}\text { rescission of inter- } \\
\text { generational pact }\end{array}$} & \multicolumn{2}{|c|}{ postfamilism } \\
\hline & $\beta$ & $\mathbf{t}$ & $\beta$ & $\mathbf{t}$ & $\beta$ & $\mathbf{t}$ & $\beta$ & $\mathbf{t}$ \\
\hline Size of network & -.099 & 2.786* & +.061 & 1.655 & -.031 & 0.867 & +.085 & 2.427 \\
\hline Age & +.038 & 1.045 & -.008 & 0.219 & +.124 & 3.406* & +.006 & 0.160 \\
\hline Anxious insecurity & -.094 & $2.636 *$ & +.171 & $4,672 * *$ & +.071 & 1.988 & +0.139 & $3.947 * *$ \\
\hline Avoidant insecurity & +.195 & $5.526 * *$ & -.066 & 1.826 & +.092 & 2.602* & -.084 & 2.421 \\
\hline Size of city & +.044 & 1.224 & -.045 & 1.211 & +.040 & 1.110 & +.031 & 0.871 \\
\hline Education & +.047 & 1.255 & +.017 & 0.442 & -.123 & $3.325 *$ & +.165 & $4.493 * *$ \\
\hline Significance (F) & & $8.466 * *$ & & $5.249 * *$ & & $6.527 * *$ & & $10.288 * *$ \\
\hline $\mathbf{N}$ & & 769 & & 743 & & 780 & & 780 \\
\hline
\end{tabular}


Table 7 - Typology of revealed dispositional states and some of their revelatory clues

\begin{tabular}{|c|c|c|}
\hline $\begin{array}{l}\text { Aspects of family } \\
\text { form } \\
\text { Revealed } \\
\text { dispositions }\end{array}$ & $\begin{array}{l}\text { Reports of main considerations when } \\
\text { individual faces a transition }\end{array}$ & $\begin{array}{l}\text { Affective/cognitive components of the general } \\
\text { mood (Crittenden, 1997) }\end{array}$ \\
\hline Sure & $\begin{array}{l}\text { Costs perceived as manageable. If costs are too } \\
\text { high, there is a recognised adjustment of goals } \\
\text { (neither denial nor anxious) }\end{array}$ & $\begin{array}{l}\text { Affective: expression of the complete range of feelings, } \\
\text { complex emotional states as well (sadness, regret, } \\
\text { happiness). } \\
\text { Cognitive: complex causal relationships (multiple } \\
\text { causality, reciprocal effects). They see external situation } \\
\text { complexity but do admit personal responsibility for } \\
\text { choices. }\end{array}$ \\
\hline Anxious & $\begin{array}{l}\text { Feeling of inadequacy, of not being able to realise } \\
\text { the type of family wished for. Preoccupation for } \\
\text { the kind of education to be transmitted. Over- } \\
\text { estimation of costs and risks. }\end{array}$ & $\begin{array}{l}\text { Affective : affectivity is used to organise thoughts and } \\
\text { behaviours. Non verbal indicators of high level of } \\
\text { activation (laughing, crying, screaming), presence of } \\
\text { emotions or moods in the speech. } \\
\text { Cognitive: confusion about causal relationships and } \\
\text { tendency to omit or distort cognitive information. }\end{array}$ \\
\hline Avoidant & $\begin{array}{l}\text { Furthering of reproductive choices, expression of } \\
\text { disinterest in children and family, as well as long- } \\
\text { term commitments. Idea of zero-sum game } \\
\text { between reproductive choices and other life } \\
\text { aspects is dominant. Clear-cut detachment from } \\
\text { affective benefits of choices. }\end{array}$ & $\begin{array}{l}\text { Affective: inhibition of negative affective manifestation. } \\
\text { Few emotions or moods in the narrative. Non verbal } \\
\text { affectivity apparently positive sometimes (e.g. Laughing } \\
\text { when uncomfortable). } \\
\text { Cognitive: organisation of behaviour according to } \\
\text { cognitive expectations: inhibition of affective states } \\
\text { which would be result in a refusal attitude when } \\
\text { negative. Emphasis on predictable regularities in } \\
\text { behaviour. }\end{array}$ \\
\hline
\end{tabular}

Glossary * P-value <.01; ** P-value <.001. 
Table 8 - Typology of family attitudes by revealed dispositional states

\begin{tabular}{|l|c|c|c|c|}
\hline $\begin{array}{l}\text { Revealed dispositions } \rightarrow \\
\text { Attitudes to family } \downarrow\end{array}$ & $\begin{array}{l}\text { Unsure anxious (grape is } \\
\text { far: handling believes) }\end{array}$ & $\begin{array}{l}\text { Unsure avoidant (grape is } \\
\text { sour: handling preferences) }\end{array}$ & Sure (grape is ok) & \\
\hline Traditional familist & 3 & 2 & 11 & $\mathbf{1 6}$ \\
\hline Individualistic familist & 2 & 10 & 6 & $\mathbf{1 7}$ \\
\hline Postfamilistic in transition & 8 & 4 & 3 & $\mathbf{1 8}$ \\
\hline Postfamilist & 0 & 0 & $\mathbf{2 5}$ & $\mathbf{5 4}$ \\
\hline
\end{tabular}

